\title{
AN EASILY USED MATHEMATICAL MODEL OF POROSITY CHANGE WITH DEPTH AND GEOLOGIC TIME IN DEEP SHALE COMPACTION
}

\author{
* Avirut Puttiwongrak ${ }^{1,2}$, Pham Huy Giao ${ }^{3}$ and Sakanann Vann ${ }^{1,2}$ \\ ${ }^{1}$ Faculty of Technology and Environment, Prince of Songkla University, Phuket Campus, Thailand \\ ${ }^{2}$ Andaman Environment and Natural Disaster Research Center (ANED), Prince of Songkla University, \\ Thailand \\ ${ }^{3}$ Geoexploration and Petroleum Geoengineering (GEPG) Programme, Asian Institute of Technology, \\ Thailand
}

*Corresponding Author, Received: 23 Jan. 2020, Revised: 18 Feb. 2020, Accepted: 01 March 2020

\begin{abstract}
Shale compaction behavior is complex and differs from sandstone. The compaction trend shows marked changes in the physical properties with increasing depth. Therefore, the porosity-depth curve in the shallow section is not well established. Several authors published porosity-depth curves in which vary considerably, particularly in the shallow part of the compaction trend. Deep shale compaction curves show deviations in the trend of porosity decreasing with depth, especially at shallow depths where mechanical compaction is dominant and this suggests that mechanical compaction is not the only factor causing porosity change and that geological time is another important factor to be considered. In this study twenty-two sets of published data on deep shale compaction up to a depth of $5 \mathrm{~km}$ from various sedimentary basins around the world were synthesized and analyzed to depict the effect of geological age on deep shale compaction curves. A time-dependent solution of the compaction equation with porosity as the variable was revisited, based on which and in combination with multivariate curve-fitting of the collected compaction data, a new and easilyused mathematical model of porosity-depth-geological time was derived. Finally, research results substantiate that a burial depth (overburden pressure) cannot be considered only for studying mechanical compaction of shales, the geological age (an effect of time) is necessary to take into account.
\end{abstract}

Keywords: Deep shale compaction, Porosity change, Geological time effect, Mathematical model

\section{INTRODUCTION}

Shale compaction can be simply described as the process, in which mud is compressed into clay and finally into shales. Generally, for the compaction of shales in a sedimentary basin mechanical compaction dominates in shallow depths, while chemical compaction would dominate in the deeper parts of the basin.

A good number of shale compaction curves have been constructed based on data collected from different sedimentary basins by many researchers to show the change of porosity with depth (e.g., [1], [2-3], [4-6]) but, it has been observed that some of the data is quite scattered and deviates from the trend of the porosity decreasing with depth, especially in the shallow part of a basin where mechanical compaction is dominant. As an example, Fig. 1 shows 22 curves of porosity versus depth compiled by the researchers in [5]. The curves in Fig. 1 suggest that mechanical compaction alone is not sufficient to explain the variations of shale compaction curves. Thus, one needs to consider not only the depth-dependent factors but also agedependent factors on deep shale porosity change.

The study reported aimed to better clarify the role of geological time on deep shale compaction curves by reanalyzing compaction data sets of

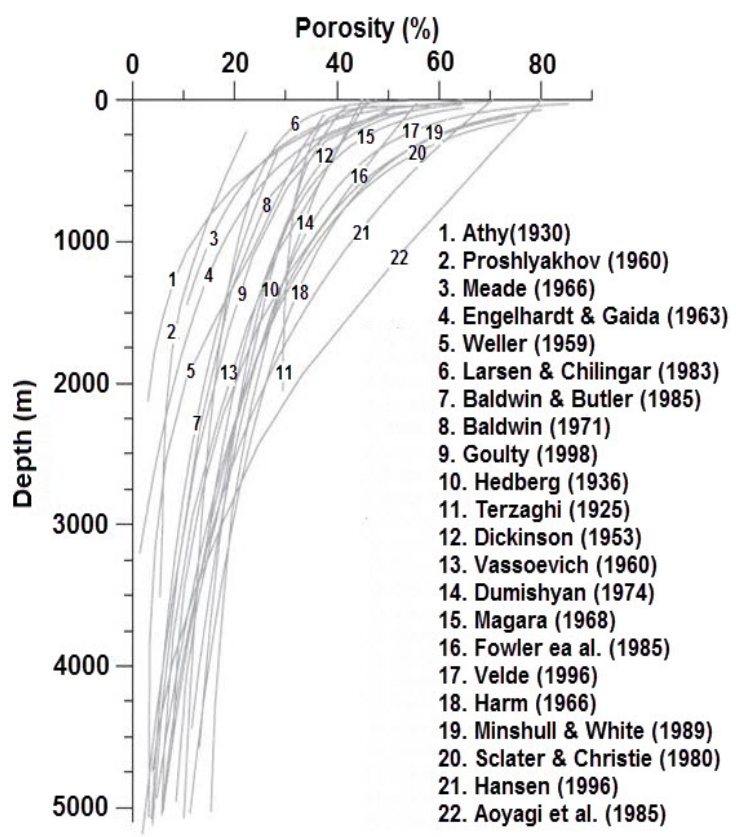

Fig.1 Mudstone compaction curves replotted from [5] 
published data of different deep shales with specific reference to their geological ages. As a result, some new mathematical equations for the porosity-depthgeological age relationship were derived and it was possible to plot deep shale compaction curves against both depth and time. To better understand the mathematical model developed in this study the following section reviews previous studies of mechanical compaction and the effect of geology on deep shale compaction.

\subsection{Mechanical Compaction}

Mechanical compaction is one of the diagenetic processes of shale compaction, which can be quantified as a function of porosity change with total overburden (burial depths), effective stress and pore pressure. A number of porosity-depth relationships have been proposed based on field observations and experimental studies. Athy [7] proposed an empirical equation of compaction as an exponential function with a negative coefficient that has been widely used for exploring the relationship of compaction of shale sediments. According to Korven [8], porosity $(\phi)$ can be expressed as a function of burial depth as shown in Eq. (1) below:

$\phi=\phi_{0} E X P(-a z)$

where $\mathrm{z}$ is the burial depth, $\phi$ is porosity, $\phi_{0}$ is the initial porosity at a datum depth and $a$ is a constant representing the local environment of basins.

In contrast to viewing porosity as a function of depth, a relationship between porosity and effective stress $\left(\sigma_{e}\right)$ has been suggested by a number of researchers including Dutta [9] and Zhang [10] as follows:

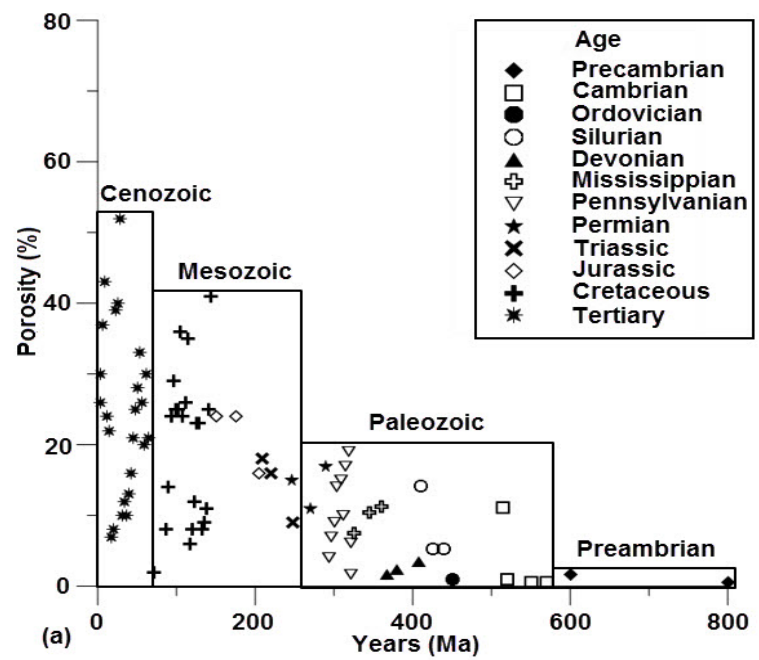

Fig.2 Porosity-geologic time plots (a) Porosity decline as a function of geological age (modified from Burst [16]); (b) Reconstruction of porosity-geological time plots from Burst [16] taking depth into consideration $\phi=\phi_{0} \operatorname{EXP}\left(-a \sigma_{e}\right)$

\subsection{Effect of Time on Shale Compactions}

Terzaghi [11] studied compaction in terms of excess pore pressure of soils and the relaxation of excess pressure over time. Versluys [12] studied the time factor in relation to the escapement of water. McCoy and Keyte [13] studied the expulsion of enormous quantities of water from compacting muds and raised doubts about the existence of a definite relationship between an overburden and the density of shales. They suggested that geologic age may also be an important factor in controlling density. It is known that, in general, in argillaceous sediments, the velocity of seismic waves increases with rock density and decreases with increasing water content. Both of these factors are usually dependent on the degree of compaction. Weatherby and Faust [14] supplied data on the increase of seismic velocities with geologic age. However, they ignored the effects of uplift and erosion. Olphen [15] studied clay mineral dehydration and concluded that many clay lattices in Paleozoic and older Tertiary sediments appear to have been completely dehydrated under normal compaction. Partial dehydration has also been observed in relatively young sediments. Because of the paucity of fully swollen clay material in Paleozoic and older Tertiary rocks and its abundance in young sediments, the clay hydration state is a function of geologic age. A pioneer in studying the effect of time on compaction processes quantitatively was Burst [16], who plotted porosity versus geological time based on a data set published by Manger [17] and suggested that the porosity of shales tends to reduce with increasing time or geological age, as can be observed in Fig. 2a. Using the same data sets of Manger [17] the porosity versus time plots were

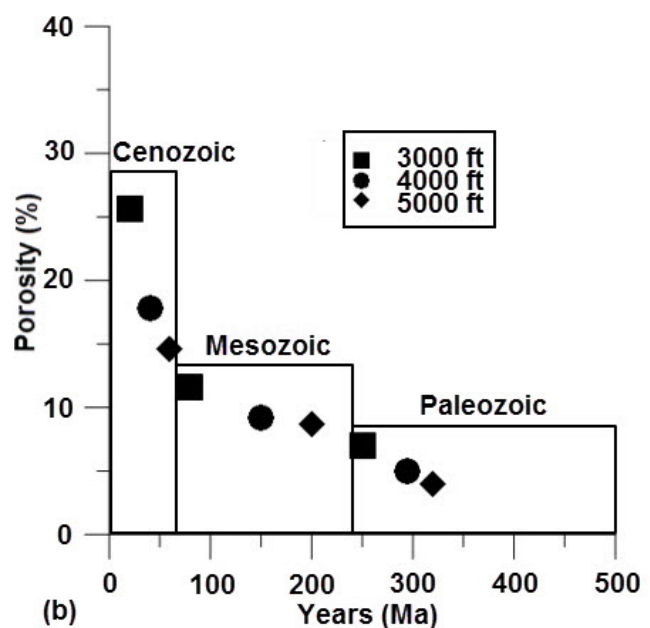


reconstructed in the present research taking the shale depth into consideration as shown in Fig. $2 b$.

\section{METHODOLOGY}

\subsection{Data Synthesis}

The shale compaction data used in this study was gathered by various researches from several sedimentary basins around the world as shown in Table 1 and Fig. 3. None of the data sets used however reported information about major erosions and unconformities. The controlling factors which probably influence scattered data and variations of compaction curves were considered and analysed, including basin type, lithology, age of stratum, the thickness of strata (i.e., maximum depth of the

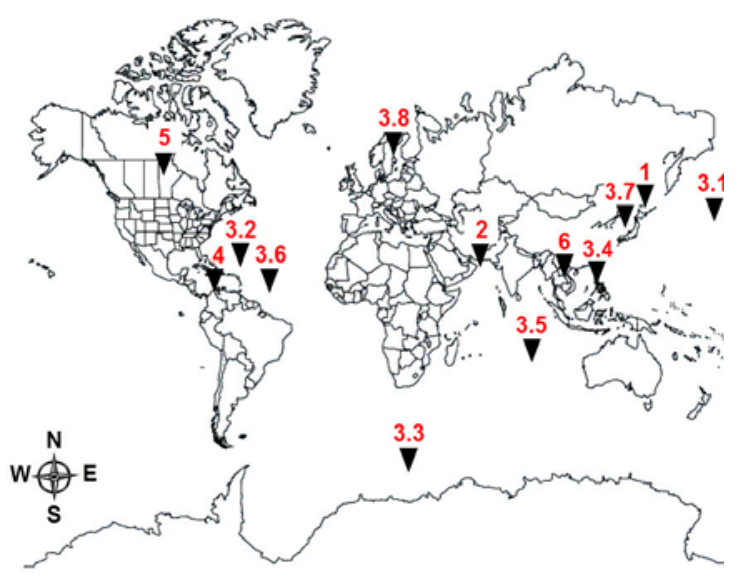

Fig.3 Data locations (corresponding to the numbers shown in Table 1) basin), and compaction factors $\left(\phi_{0}, a\right)$ as shown in Table 1.

\subsection{Porosity Acquisition and Basin Information}

Porosity and density have been long considered to be the main indicators of the compaction of sediments. To investigate the possible effect of geological age, six data sets were revisited as listed and numbered in Table 1 with their original data sources. Porosity data set No. 1 (see Table 1) was taken from core samples obtained at 16 wells in the Akita oil field, Japan. The densities of the samples were measured within a few hours of being collected from wells and were then converted into porosity data. The geological information in data set No. 1 can be found in [4]. The samples ranged from shale of the Sasaoka formation to the black shale of the Funakawa formation. The wells from which the samples were taken are located near the crest of a gentle anticline, where no structural disturbances in the sediments could be identified and the density distribution in each well seemed to be normal.

Porosity data set No. 2 (see Table 1) which was from the work of Hamilton [18] was estimated based on seismic velocity data using an empirical relationship which first converted the seismic velocity to bulk density, which was then further converted to porosity. Data set No. 2 was taken from abyssal plain sediments in the Makran accretionary prism of the Northwestern Indian Ocean, where the oceanic Arabian plate is subducting shallowly northwards beneath the

Table 1 Data used in this study

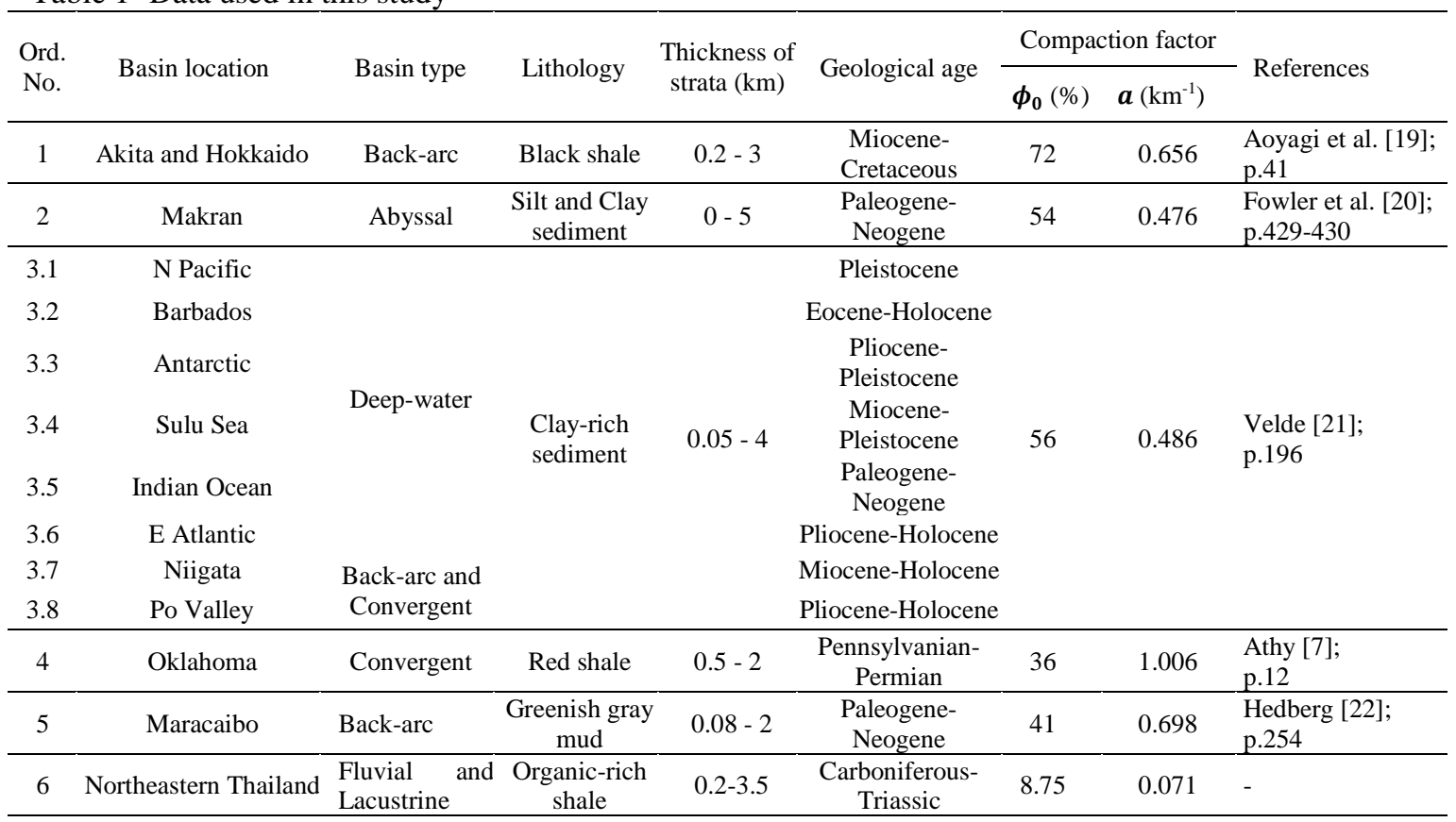


continental Eurasian plate. The abyssal plain sediments were undeformed sediments and very little erosion had taken place. Consequently, they do not exhibit major internal deformation and did not undergo any tectonic consolidation.

The porosity data comprising the data sets grouped together as No. 3, from 3.1 to 3.8 (see Table 1), were obtained from several basins, sampled as part of the Ocean Drilling Program (ODP) and the Deep Sea Drilling Project (DSDP). The porosity data were determined by consolidation tests in a laboratory. The basin histories of the No. 3 group data set stated that the samples had not yet been affected by diagenesis as they were in the beginning stages of particle re-arrangement.

In data sets Nos. 4 \& 5 (see Table 1), the porosities were estimated from density data using different methods. The bulk density in data set No. 4 was acquired by weighing a sample in mercury with a Jolly balance, a sufficient mass being suspended to submerge the sample, while, for data set No. 5 Melcher and pycnometer methods were used to measure the bulk density and absolute density, respectively. Data set No. 4 was collected in Oklahoma and the basin information stated that all the samples studied were taken from areas of structural deformation and some of the compaction may have resulted from vertical and lateral pressures in the earth's crust. The samples were acquired from wells in the Mervine, South Ponca, Thomas, Garber, and Blackwell fields. The sediments range from Permian age to the base of Pennsylvanian age with no intervening unconformity. Data set No. 5 was obtained from the geological laboratory of the Venezuela Gulf Oil

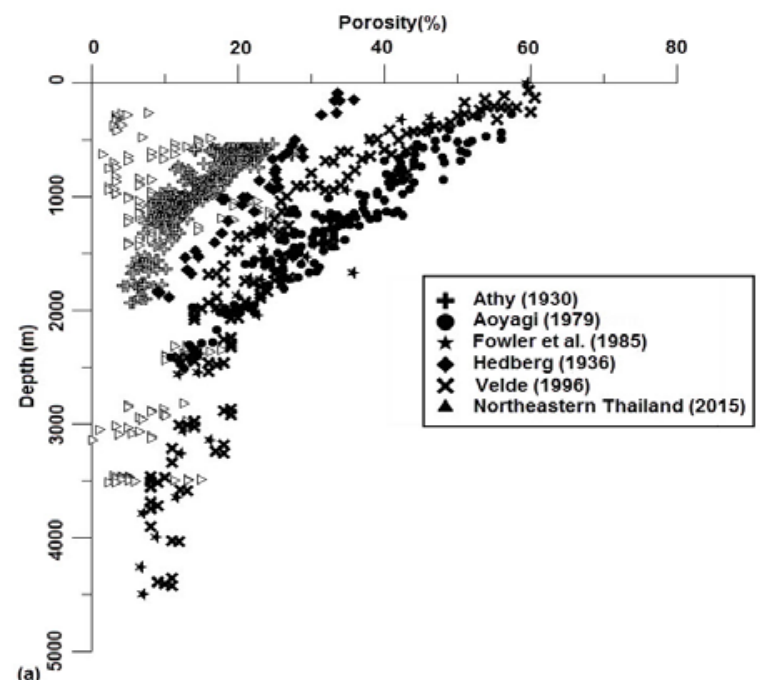

Company based on the study of core samples of Tertiary shales from wells drilled in the large geosynclinals basins of Venezuela. The samples were taken from a deep test in undisturbed and essentially horizontal Tertiary strata far away from areas of major tectonic disturbance and the strata consisted in large part of mudstones that were free from appreciable sand impurity. In addition, the absence of major unconformities in the section makes it possible to assume that the existing overburdens are maximum overburdens.

Finally, data set No. 6 (see Table 1) consists of shale data from several basins in the northeastern part of Thailand. The data were taken by density logging, sonic logging, and neutron logging. Shales in the north-eastern part of Thailand are locally thick, organic-rich, dry gas prone, deeply buried, and over pressured. They were initiated during the Middle Paleozoic, with widespread deposition of clastic and carbonate sedimentary rocks. Tectonic extension during the Early Permian broke the basin apart into numerous horst and graben blocks separated by high-angle normal faults.

\subsection{Identification of Geological Time Effect on Porosity versus Depth Curves}

The factors that can influence shale compaction are shown in Table 1 and include basin type, lithology, thickness of strata, age of stratum and compaction factors. The compaction factors, i.e. the porosity of the shales at datum depth $\left(\phi_{0}\right)$ and the constant value of the exponential function $(a)$, were determined by fitting curves from Eq. (1).

To identify the effect of geological time on the porosity versus depth curves, the data were first divided into two major groups, old mudstones (Paleozoic and Mesozoic) and young mudstones

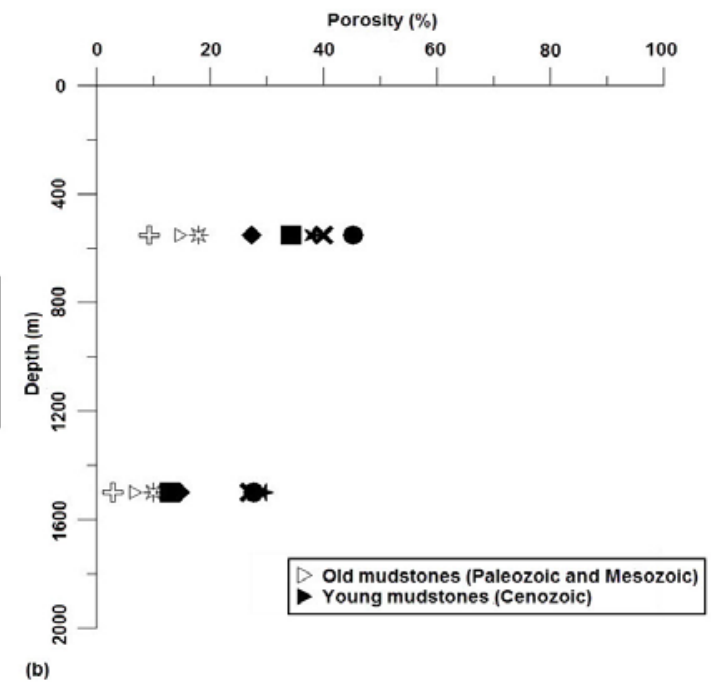

Fig. 4 Data plots of different times on porosity-burial depth graph a) Effect of time on scattered data b) Depth specification to reveal the geological time effect 
(Cenozoic) as shown in Fig. 4a, from which a rather clear separation between the two groups can be observed (the empty symbol stands for the old mudstones, and the filled symbols for the old mudstones). In Fig. 4b the data at two depths of 500 $\mathrm{m}$ and $1,500 \mathrm{~m}$ were plotted to better depict the separation between the curves of porosity versus depth due to geological time.

\subsection{A Time-Dependent Solution of The Deep Shale Compaction Equation}

The compaction of clays can be successfully described by Terzaghi's equation [11]. To reveal the effect of time on shale compaction, the following two assumptions were made: the permeability of mud sediments is much smaller than that of sandy soils, and changes of water saturation and relaxation of excess pressure due to changes in stress state take place much slower in mudstones than in aquifer sediments. The excess pressure (u) in compacting beds of clay is a function of time (t) and depth (z) as shown in Eq. (3), where $\boldsymbol{c}_{\boldsymbol{v} \boldsymbol{c}}$ is the coefficient of compaction.

$$
\frac{\partial u}{\partial t}=c_{v c} \frac{\partial^{2} u}{\partial t^{2}}
$$

Eq. (3) can be rewritten as Eq. (4) below using the porosity $(\phi)$ instead of the excess pressure $(u)$ as a function of time and depth of slow compaction [23] as follows:

$$
\begin{aligned}
\frac{\partial \phi}{\partial t} & =\frac{\lambda^{\prime} \partial^{2} \phi}{\partial z^{2}} \\
\lambda^{\prime} & =\frac{\lambda\left(1-\phi_{0}\right)^{2}}{\phi_{0}, \lambda}=\frac{k_{0}}{M, k_{0}}=\frac{K_{0} \gamma_{w}}{\mu}
\end{aligned}
$$

where $\lambda$ is the compaction number, $\phi_{0}$ is the initial porosity, $M$ is the sedimentation rate, $\mu$ is the fluid viscosity, $\gamma_{\mathrm{w}}$ is the unit weight of water, $K_{0}$ is the initial permeability, and $k_{0}$ is the initial permeability coefficient. The variable separation method can be used to solve Eq. (4), as follows:

$$
\begin{aligned}
& \phi(z, t)=Z(z) T(t) \\
& \frac{T^{\prime}(t)}{\lambda^{\prime} T(t)}=\frac{Z^{\prime \prime}(z)}{Z(z)}=\text { Constant value }(b)
\end{aligned}
$$

The following solutions can then be obtained:

$$
\begin{aligned}
& T(t)=C_{2} E X P\left(\lambda^{\prime} a^{2} t\right) \\
& Z(z)=C_{1} E X P(a z)+C_{3} E X P(-a z)
\end{aligned}
$$

where: $C_{1}, C_{2}$, and $C_{3}$ are constants. As the burial depth cannot decrease for compaction (a negative sign), the second term of Eq. (9) could be unknown. Substituting Eq. (8) and Eq. (9) into Eq. (6), a mathematical expression of the compaction of shales with both time and depth can be established as follows:

$\phi(z, t)=\phi_{0} \operatorname{EXP}\left(-\left(a z+a^{2} \lambda^{\prime} t\right)\right)$

If the time factor is omitted, Eq. (10) will be reduced to Athy's model as shown in an Eq. (1) ignoring the mutual dependence of $z$ and $t$ in a geological process. An actual set of data from a well represents geological processes and histories that the stratigraphic succession passed through. Hence, as long as actual data is used, ignoring the mutual dependence of $\mathrm{z}$ and $\mathrm{t}$ can be implicitly expressed in the analysis of the actual data based on Eq. (10) and is canceled in the evaluation of constants $\phi_{0}$ and $a$, etc.

\section{RESULTS AND DISCUSSION}

As time is a cause of scattered data in relation to shale compaction in different basins, in this section the influence of time on shale compaction will be demonstrated and the variations of the compaction curves of shales, especially in the shallow part of the basins will be explained.

Table 2 Assumed parameters

\begin{tabular}{ccc}
\hline Parameters & Value & Unit \\
\hline Constant value of exponential function $(\boldsymbol{a})$ & 0.48 & $\mathrm{Km}^{-1}$ \\
Initial porosity $\left(\boldsymbol{\phi}_{\mathbf{0}}\right)$ & 65 & $\%$ \\
Unit weight of water $\left(\gamma_{w}\right)$ & $1 \times 10^{4}$ & $\mathrm{~N} / \mathrm{m}^{3}$ \\
Initial permeability $\left(K_{0}\right)$ & 0.38 & $\mu \mathrm{D}$ \\
Fluid viscosity $(\mu)$ & $0.8 \times 10^{-3}$ & $\mathrm{~Pa} \cdot \mathrm{s}$ \\
Sedimentation rate $(M)$ & 1 & $\mathrm{~mm} / \mathrm{y}$ \\
\hline
\end{tabular}




\subsection{Time Effect on Porosity as Function of Depth}

As demonstrated above, time is an effective factor controlling shale compaction, causing the compaction curves to scatter. The parameters of a standard case of a slow compaction model are listed in Table 2; they are initial porosity $\left(\phi_{0}\right)$, initial permeability $\left(K_{0}\right)$, fluid viscosity $(\mu)$, unit weight of water $\left(\gamma_{\mathrm{w}}\right)$, sedimentation rate $(M)$, and the constant value of the exponential function $(a)$. It was assumed that those parameters are the same values for various basins in order to use them in Eq. (10) as a test.

Shale compaction curves varying with time were drawn as shown in Fig. 5. The calculated data plots (shale compaction curves varying with time) with actual data are shown in Fig. 6. The graph

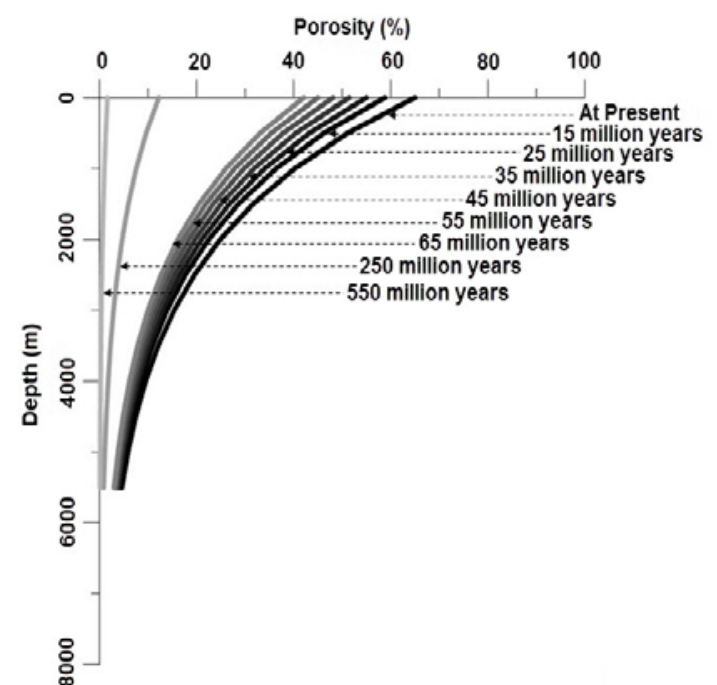

Fig. 5 Shale compaction curves varying with times

shows an acceptable match between the calculated and actual data. The scattering of actual data can also be explained as the effect of time on shale compaction (from Table 1), but in this study, the same assumed parameters were used to constrain only the influence of the time factor on shale compaction. An increment of 100 million years was selected to clearly identify the effect of time on shale compaction. Furthermore, the variations of

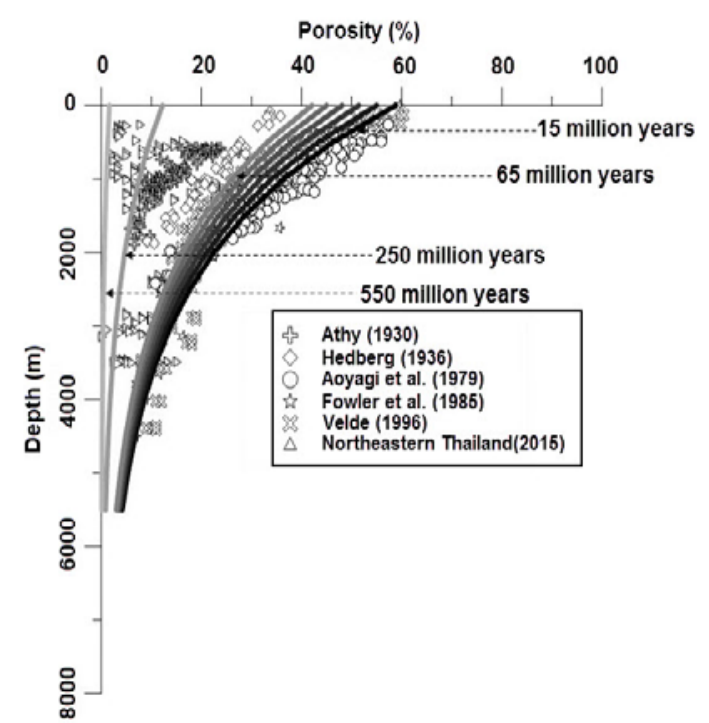

Fig. 6 Shale compaction curves varying with times on scattered data of shale compaction

[5]'s curve can also be explained by the shale compaction curves varying with time. Athy [7]'s curve in Fig. 1, which related to a Paleozoic shale, is consistent with shale compaction curves with starting times in the Paleozoic period (250 Ma). Similarly, the curves of Velde [21], Hedberg [22] and the researchers in [20] relating to Cenozoic shales, are consistent with the variation within shale compaction curves for the Cenozoic period (from 0 to $65 \mathrm{Ma}$ ).

The summary is, therefore, that time is an important factor controlling compaction processes to which more attention should be paid in studying the mechanism of shale compaction, particularly in considering a long geologic interval in the order of 100 million years. However, for shorter periods in order 1 to 10 million years, the value of $a^{2} \lambda^{\prime}$ would be negligible. For time periods in excess of 100 million years, the time effect becomes visible in the actual stratigraphic succession.

\subsection{Calibration of the Porosity-Depth-Geological Time Model}

Two data sets of porosity versus depth and geological time were considered, i.e., (i) the data set

Table 3 Comparison between assumed and calculated parameters

\begin{tabular}{cccc}
\hline Parameters & Assumed value & Calculated value & Unit \\
\hline Constant value of exponential function $(\boldsymbol{a})$ & 0.48 & 0.40 & $\mathrm{Km}^{-1}$ \\
Initial porosity $\left(\boldsymbol{\phi}_{\mathbf{0}}\right)$ & 65 & 55.9 & $\%$ \\
Initial permeability $\left(K_{0}\right)$ & 0.38 & 0.13 & $\mu \mathrm{D}$ \\
$\lambda^{\prime}$ & 0.029 & 0.026 & - \\
\hline
\end{tabular}


calculated using Eq. (10) with the input parameters as initially assumed in Table 2; and (ii) a grouped data set based on all the published data mentioned earlier and presented in Fig. 6. By taking the natural logarithm of both sides of Eq. (10) the following equation is derived:

$\ln \phi=\ln \phi_{0}-a z-a^{2} \lambda^{\prime} t$

The newly transformed Eq. (1) was employed in a back-analysis to estimate $\phi_{0}, K_{0}, a$, and $\lambda^{\prime}$ as follows: two sets of calculated and collected data were plotted in a 3D plot of porosity versus depth and geological time with logarithmic scales as shown in Fig. 7. By multivariate curve fitting, the best-fitted values of $\phi_{0}, K_{0}, a$, and $\lambda^{\prime}$ were found as presented in Table 3 with $\mathrm{R}^{2}$ equal to 0.70 . From the results a new and simple model of porosity change with depth and geological time was obtained as follows:

$\ln \phi=4.023-0.4 z-0.0042 t$

where $\mathrm{z}$ is the depth of shale in $\mathrm{km}^{-1} ; t$ is geological time in Ma.

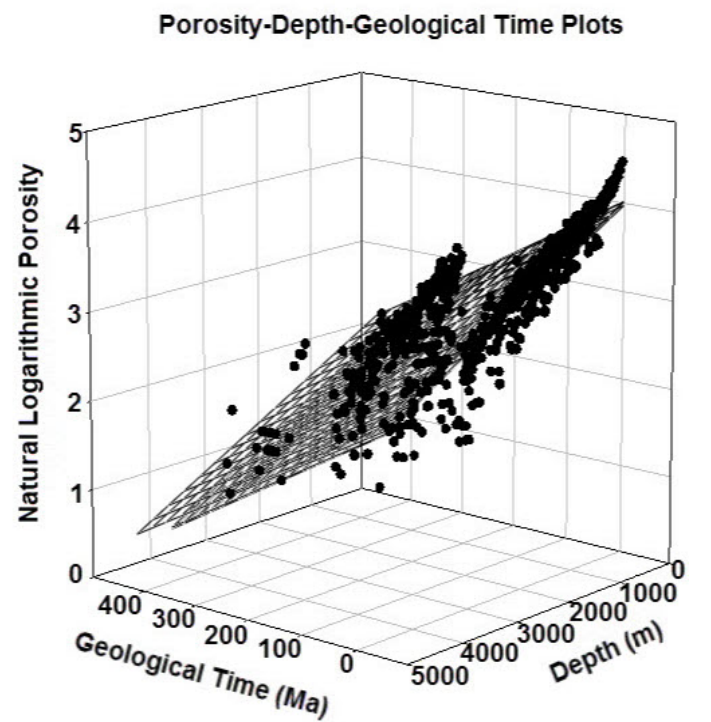

Fig. 7 Three-Dimension (3D) plot of porosity versus depth and geological time and plan curve fitting

\section{CONCLUSION}

A number of compaction curves of deep shales with geological ages varying from Tertiary to Precambrian from different sedimentary systems, derived from published data sets were synthesized and reanalyzed and this study was thus able to establish that while the compaction curves show a consistent trend of porosity decreasing with depth the curves are not exactly the same and are quite scattered, especially in shallow depths where mechanical compaction is expected to be predominant. In other words, the overburden or burial depth alone is not sufficient to describe the shape of the deep shale compaction curve, for which geological time is another important influencing factor.

The effect of geological time was explored and confirmed its role by representing the deep shale compaction data up to a depth of $5 \mathrm{~km}$. To confirm this finding, the compaction equation was used with porosity as the main variable instead of pore pressure and its time-dependent solution was revisited. By using the mathematical solution in combination with a plane curve fitting of the collected porosity data versus depth and geological age a new and easily-used model of porosity versus depth and geological time was derived. The expectation is that this model can be useful for wide applications in petroleum system modeling, geological modeling, petro-physics, and reservoir simulation.

\section{ACKNOWLEDGMENTS}

This research would like to express the Department of Minerals and Fuels (DMF), Thailand who provided data. We thank our colleagues Mr. Hiromi Honda and Prof. Toshifumi Matsuoka who provided insight and expertise that greatly assisted the research. In addition, we are thankful for our gratitude towards the members of ESSAND and ANED, Prince of Songkla University Phuket campus, for their kind co-operation and encouragement which helped us in the completion of this research. This work was supported by the Research and Development Office (RDO), Prince of Songkla University [grant numbers PPK570718S]. Finally, we would like to thank PSU English Clinic for editing English proofreading.

\section{REFERENCES}

[1] Baldwin B., and Butler C. O., Compaction curves. AAPG Bulletin, Vol. 69, Issue 4, 1985, pp. 622-626.

[2] Dutta T., Mavko G., Mukerji T., and Lane T., Compaction Trends for Shale and Clean Sandstone in Shallow Sediments, Gulf of Mexico. The Leading Edge, Vol. 28, Issue 5, 2009, pp. 590-596.

[3] Dzevanshir R. D., Buryakovskiy L.A., and Chilingarian G.V., Simple Quantitative Evaluation of Porosity of Argillaceous Sediments at Various Depths of Burial. Sedimentary Geology, Vol. 46, Issues 3-4, 1986, pp. 169-175.

[4] Miyazaki H., Gravitational compaction of the Neogene muddy sediments in Akita oil fields, northeast Japan. Journal of geosciences, Vol. 9, 1966, pp. 1-23. 
[5] Mondol N. H., Bjorlykke K., Jahren J., and Hoeg K., Experimental Mechanical Compaction of Clay Mineral Aggregates-Changes in Physical Properties of Mudstones during Durial. Marine and Petroleum Geology, Vol. 24, Issue 5, 2007, pp. 289-311.

[6] Skempton A.W., Jones O. T., Notes on the Compressibility of Clays. Journal of Geological Society, 1944, pp. 119-135.

[7] Athy L.F., Density, Porosity, and Compaction of Sedimentary Rocks. AAPG Bulletin, Vol. 14, Issue 1, 1930, pp. 1-24.

[8] Korvin G., Shale Compaction and Statistical Physics. Geophysical Journal International, Vol. 78, Issue 1, 1984, pp. 35-50.

[9] Dutta N.C., Geopressure Prediction Using Seismic Data: Current Status and the Road Ahead. Geophysics, 67, Issue 6, 2002, pp. 20122041.

[10] Zhang J., Pore Pressure Prediction from Well Logs-Methods, Modifications, and New Approaches. Earth-Science Reviews, Vol. 108, Issue 1-2, 2011, pp. 50-63.

[11] Terzaghi K., Theory to Practice in Soil Mechanics, 1st ed. John Wiley and Sons, New York, 1925, pp. 425.

[12] Versluys J., A hypothesis Explaining Some Characteristics of Clay, in Proc. Koninklijke Nederlandse Akademie Van Wetenschappen Te, 1927, pp.104-112.

[13] McCoy A. W., and Keyte W.R., Present Interpretations of the Structural Theory for Oil and Gas Migration and Accumulatlion. AAPG Bulletin, 1934, pp. 279-282.

[14] Weatherby B.B., and Faust L.Y., Influence of Geological Factors on Longitudinal Seismic Velocities. AAPG Bulletin, Vol. 19, Issue 1, 1935, pp. 1-8.
[15] Olphen H.V, Compaction of Clay Sediments in the Range of Molecular Particle Distances, in Clays and Clay Minerals, in Proc. 11th National Clays and Clay Mineral Conference, 1963, pp.178-187.

[16] Burst J.F., Diagenesis of Gulf Coast Clayey Sediments and its Possible Relation to Petroleum Migration, Vol. 53, Issue 1, AAPG Bulletin, 1969, pp. 73-93.

[17] Manger G. E., Porosity and Bulk Density of Sedimentary Rocks. USGS, 1963, pp. 34-40.

[18] Hamilton E.L., Sound Velocity-Density Relations in Sea-floor Sediments and Rocks. The Journal of the Acoustical Society of America, Vol. 63, Issue 2, 1978, pp. 366-377.

[19] Aoyagi K., and Asakawa T., Primary Migration Theory of Petroleum and its Application to Petroleum Exploration. Organic Geochemistry, Vol. 2, Issue 1, 1979, pp. 33-43.

[20] Fowler S.R., White R.S., and Louden, K.E., Sediment Dewatering in the Makran Accretionary Prism. Earth and Planetary Science Letters, Vol. 75, Issue 4, 1985, pp. 427438.

[21] Velde B., Compaction Trends of Clay-rich Deep Sea Sediments. Marine Geology, Vol. 133, Issue 3-4, 1996, pp. 193-201.

[22] Hedberg H.D., Gravitational Compaction of Clays and Shales. American Journal of Science, Vol. 31, Issue 184,1936, pp. 241-287.

[23] Fowler A.C., and Yang X.S., Fast and Slow Compaction in Sedimentary Basins. SIAM Journal on Applied Mathematics, Vol. 59, Issue 1, 1998, pp. 368-385.

Copyright (C) Int. J. of GEOMATE. All rights reserved, including the making of copies unless permission is obtained from the copyright proprietors. 